\title{
Das Paixões Humanas ao Vazio lluminador: Reflexões e Apontamentos a Partir do Budismo Tântrico
}

\author{
From Human Passions to Enlightening Emptiness: \\ Thoughts and Notes on Tantric Buddhism
}

\author{
Maria Lucia Abaurre Gnerre ${ }^{2}$ \\ Rafael Parente Ferreira Dias ${ }^{3}$
}

RESUMO

Este artigo tem como objetivo fazer uma análise das paixões humanas aplicadas aos ensinamentos do budismo tântrico. $O$ tantrismo busca na transmutação dos desejos e das paixões um valioso suporte soteriológico, capaz de emancipar a consciência humana de todos os condicionamentos psicológicos, libertando-a dos apegos sensoriais e da instabilidade mental. A filosofia do Tantra estimula a prática meditativa com vistas a ampliar a compreensão do discípulo, bem como comprovar a natureza oscilante e vazia de todos os fenômenos, objetivando, em última análise, a aquisição da insuperável iluminação. Para corroborar com nosso posicionamento teórico, utilizaremos, neste artigo, o suporte bibliográfico de pesquisadores acadêmicos e mestres da tradição mahāyāna e vajrayāna, a fim de aprofundar os ensinamentos do tantra budista.

PALAVRAS-CHAVE: Budismo. Paixão. Transmutação. Iluminação.

\section{FROM THE HUMAN PASSIONS TO THE ENLIGHTENMENT VOID: REFLECTIONS AND TESTS FROM THE TANTRIC BUDDHISM}

\footnotetext{
ABSTRACT

This article aims to make an analysis of the human passions applied to the teachings of Tantric Buddhism. Tantrism seeks in the transmutation of desires and passions a valuable soteriological support capable of emancipating human consciousness from all psychological conditioning, freeing it from sensory attachments and mental instability. The philosophy of Tantra stimulates meditative practice with a view to broadening the understanding of the disciple, as well as proving the oscillating and empty nature of all phenomena, ultimately

${ }^{1}$ Recebido em 30/05/2017. Aprovado em 30/09/2017.

${ }^{2}$ Doutora em História. Professora do departamento de Ciências das Religiões da Universidade Federal da Paraíba. Email: marialucia.ufpb@gmail.com

3 Doutorando em Ciências das Religiões. Professor da Universidade Estadual de Roraima. Email: rafael.dias@uerr.edu.br
} 
aiming at the acquisition of unsurpassed enlightenment. In order to corroborate our theoretical positioning, we will use in this article the bibliographic support of academic researchers and masters of Mahayana and Vajrayana tradition in order to deepen the teachings of Buddhist Tantra.

KEYWORDS: Buddhism. Passion. Transmutation. Enlightenment.

\section{Introdução}

Ao longo da História, diversas religiões têm relegado à humanidade, por meio de suas sagradas escrituras ou através de tradições orais, ensinamentos que servem como base moral e espiritual para seus seguidores. Contudo, muitas formas religiosas, dentre elas o Budismo, dispõem de um conjunto de ensinamentos iniciáticos ou secretos que são pouco difundidos no âmbito de suas escrituras ortodoxas $^{4}$ e que, justamente por isso, restringem-se a pequenos grupos, os quais teriam acesso a aspectos místicos, esotéricos, os quais estariam velados ao grande público. No âmbito budista, o Tantra configura-se como um desses singulares conhecimentos, cuja profundidade moral, epistêmica e soteriológica ganha contornos próprios, bem distantes daqueles preconizados pela antiga tradição theravāda. Porém, devido a certos equívocos, tais ensinamentos sofreram severas restrições e incompreensões, sobretudo após sua chegada ao ocidente no contexto do chamado "Orientalismo" do século XIX, ocasionando, assim, a escassa tradução de seus escritos, bem como a falta de interesse por um real aprofundamento filosófico. Ademais, as pesquisas acadêmicas sobre o tema, principalmente no cenário intelectual brasileiro, estão longe de serem satisfatórias, há pouca literatura traduzida para o português, prejudicando a disseminação do conhecimento ao grande público, restringindo-se, principalmente, ao seleto círculo esotérico budista e hindu.

Este artigo pretende aguçar as discussões acadêmicas sobre o budismo tântrico, sobretudo no que diz respeito às paixões humanas. Nesse sentido, nosso estudo gravitará em torno de questões subjetivas e sutis, ligadas ao desejo e ao

4 Referimo-nos à Tripitaka, que está dividida em três partes (Vinaya-Pitaka, Sutta-Pitaka e AbidhamaPitaka), considerada a mais tradicional coletânea de textos do cânon ortodoxo budista, escrita originariamente em língua páli e com traduções sânscritas, chinesas e tibetanas. $\bigcirc$ Vinaya-Pitaka, por exemplo, trata da disciplina monástica e possui um forte conteúdo moral, bem distante da abordagem tântrica apresentada em nosso trabalho.

${ }^{5}$ A respeito do conceito de Orientalismo, Cf. SAID, 1990. 
domínio das emoções, as quais possuem relevância decisiva no contexto das religiões orientais. Tentaremos demonstrar que as paixões humanas ${ }^{6}$ e os desejos, na perspectiva tântrica, são um fenômeno que, devidamente trabalhado, pode servir para o desenvolvimento da espiritualidade. A inclusão dos prazeres sensoriais como método de ascese espiritual é uma prática comum para muitas escolas budistas que seguem os ensinamentos tântricos; a clássica repressão dos prazeres (muito comum nas grandes religiões monoteístas] não encontra eco na tradição tântrica. Portanto, no presente trabalho, tentaremos expor, em linhas gerais, esse milenar conhecimento e todas as implicações filosóficas e existenciais que dele derivam.

\section{Tantrismo $x$ Eurocentrismo}

A palavra sânscrita Tantra $^{7}$ é polissêmica e pode ser traduzida como "continuar", "esticar", "multiplicar", indica algo sem interrupção. O XIV Dalai Lama (1988) sugere que essa não-interrupção oriunda do termo tantra estaria ligada à essência última da mente, dotada de potencialidade ilimitada. Segundo Mircea Eliade (1996, p. 172), "o tantra seria 'aquele que estende o conhecimento"'. Gavin Flood (2006) afirma que a palavra tantra designaria um "tear", onde a raiz tan, além de significar "estender" ou "esticar", estaria relacionado com Tanu, "o corpo". Analogamente, Georg Feuerstein afirma que, em um aspecto mais corriqueiro, a raiz sânscrita tan poderia ser traduzida por "teia", "tecido", "trama", por outro lado, também estaria relacionada com o termo tantu (fio ou cabo). $\bigcirc$ autor admite também a tradução do termo como "continuidade", designando o conjunto harmonioso entre transcendência e imanênciå .

Do ponto de vista filosófico, o Tantrismo pode ser definido como um conjunto de textos ${ }^{9}$ e práticas místico-esotéricas, comportando ritos e ensinamentos secretos com vistas à experimentação direta da realidade última da natureza. Snellgrove define o tantrismo da seguinte forma: "Eles contêm fórmulas mágicas, descrições de seres divinos e um conjunto de divindades organizadas para o uso ritualístico e meditativo" (SNELLGROVE, 1957, p. 55, tradução nossa). Geshe Kelsang Gyatso acrescenta:

\footnotetext{
${ }^{6}$ Por paixões humanas entendemos aqui todos os apegos sensoriais (dinheiro, mulheres, carros etc.) e não apenas algo ligado à sexualidade.

${ }^{7}$ O termo tantra foi introduzido pela primeira vez no idioma inglês no ano de 1799 e, desde então, permanece um campo aberto para interpretações que, por vezes, soam demasiadamente equivocadas [GUENTHER \& TRUNGPA, 2003, p. 15).

${ }^{8}$ Cf. FEUERSTEIN, 1998, p. 2.

9 Importante salientar que, quando falamos em "tantra", não podemos perder de vista sua correlação literária, isto é, que o tantra também é definido como uma coletânea de textos tardios da tradição budista mahāyāna e vajrayāna.
} 
O Tantra é definido como uma realização interior que atua para impedir aparências e concepções comuns e para realizar as quatro completas purezas. Embora as escrituras tântricas de Buda sejam algumas vezes denominadas "Tantra" porque revelam as práticas tântricas, o Tantra propriamente dito é, necessariamente, uma realização interior que protege os seres vivos das aparências e concepções comuns, que são a raiz dos sofrimentos do samsara. (GYATSO, 2016, p.153, 154]

Além dos mantras, meditações, visualizações e rituais, a filosofia tântrica, desde suas remotas origens, sempre teve uma relação singular com as paixões humanas, talvez por isso o receio de Siddharta em transmitir esse conhecimento ao povo em geral. $\bigcirc$ estudo do tantra é particularmente trabalhoso devido a esse hermetismo que o acompanha, o mistério parece ser o inseparável companheiro destes ensinamentos. No tantrismo existe uma marcada tendência ao desvio, ao questionamento das bases mais profundas do budismo, indicando um caminho ignorado pelas duras regras monásticas que ainda hoje existem no interior da ordem. Jean Bousselier, exaltando essas impactantes transformações dos textos tântricos dentro da tradicional visão budista, adverte:

Desde o início do século VIII, há um ponto a respeito do qual a maioria das escolas tântricas, deliberadamente, tomava a direção oposta aos ensinamentos do budismo anterior: é a introdução de um dualismo erótico que logo deveria assumir uma grande importância. Desde a origem, todos os grandes mestres budistas haviam denunciado a paixão erótica, quase sempre com veemência, como sendo o laço mais poderoso que prende o ser ao ciclo das transmigrações e combatido a sexualidade (BOUSSELIER, 2002, p. 170).

A recusa dos valores tradicionais transformou os mestres tântricos e seus métodos singulares de desenvolvimento espiritual em uma segunda via, um caminho por vezes, estranho, mas atraente aos olhos do monge cansado das extasiantes regras monásticas dos sutras. $\bigcirc$ tantra buscou romper com os antigos paradigmas ortodoxos do budismo primitivo, introduzindo em seu cânon a satisfação das paixões e desejos como método de ascese mística:

[...] buscou-se conciliar gozo e desprendimento, consumo e libertação: bhukti e mukti [...] em vez de percorrer durante milhares e milhares de vidas o caminho que conduz ao Despertar, trata-se, para "o homem necessitado" que somos, de tomar o caminho direto. Esse consiste em descobrir na própria servidão das paixões a energia cósmica, o dinamismo positivo que as anima e que pode, eventualmente, suspender a consciência de ser "eu-fulano" e nos libertar da dualidade [...] Há ouro escondido na lama das paixões (GUY BUGAULT \& LAKSHMI KAPANI, 2007, p. 175, 176). 
Segundo Herbert V. Guenther e Chögyam Trungpa, desde o fim do século XVIII, o Tantra recebeu interpretações equivocadas, fruto de um preconceito moralizante motivado pela tendência colonizadora cristã̃ ${ }^{10}$. Edward Said (1990) adverte que o termo "orientalismo" é uma construção cultural e política do ocidente. Conforme o autor, o conceito "Oriente" transcende a circunferência geográfica, inserindo-se numa perspectiva imaginativa, construída/representada pelo Ocidente, mais precisamente por franceses, ingleses e norte-americanos. Caracteriza-se por representar o mundo oriental como o exótico, o inferior, o misterioso, que, mesmo contendo um brilho próprio, necessitaria de "reparos". De fato, as lentes colonizadoras e preconceituosas dos intérpretes cristãos do século XVIII deturparam as verdadeiras aspirações da literatura tântrica.

O olhar apressado, a leitura descomprometida ou mesmo o preconceito religioso fizeram dos textos tântricos um labirinto espinhoso de fórmulas e ensinamentos de difícil adesão por parte de outras tradições religiosas. Não podemos "ajustar" o tantra, transformá-lo em uma filosofia de bom gosto, conforme nossas exigências moralizantes. $\bigcirc$ tantrismo possui a sua própria lógica interna, seus trajes teóricos não admitem remendos, foram feitos sob medida, por especialistas na arte da intuição mística, qualquer intervenção causaria um descompasso indesejado, a proposta originária sofreria um abalo irreparável, colocando em risco os efeitos benéficos de suas milenares práticas iniciáticas. Infelizmente, o Tantra não é apenas mal interpretado pelos cristãos ortodoxos, mas também pelo grande público da Índia e do Tibete, como podemos evidenciar no comentário de Geshe Kelsang Gyatso:

Embora o Tantra seja muito popular, poucas pessoas compreendem seu verdadeiro significado. Algumas negam os ensinamentos tântricos de Buda, ao passo que outras fazem mau uso desses ensinamentos, com o objetivo de conquistas mundanas; e muitas pessoas estão confusas sobre a união das práticas de Sutra e de Tantra, acreditando equivocadamente que o Sutra e o Tantra são contraditórios (GYATSO, 2016, p.152).

A linguagem simbólica, a descrição de centros magnéticos, a anatomia oculta (prāṇā, nādī, cakras etc.]", toda essa tecnologia mística torna mais trabalhosa a compreensão, pois estamos tratando de abordagens sutis, distantes da apreensão dos sentidos. Agregado a tais sutilezas, vemos o preconceito contra a visão mais abrangente do tantrismo no que diz respeito à moralidade, aos prazeres, e

${ }^{10}$ Cf. GUENTHER V. Herbert \& TRUNGPA 2003, p. 15.

"Desenvolve-se na Índia desde os períodos mais remotos, uma elaborada anatomia do corpo sutil, composta por Chackras - que são rodas ou centros de energia, e nadis, os canais por onde circula esta energia, também denominada prāna . Durante a idade média da Índia, quando se desenvolve o tantrismo, este estudo da anatomia sutil com seus diversos elementos será intensificado, principalmente com o surgimento do Hatha-Yoga, com relação à anatomia sutil do corpo humano [GNERRE, 2010, p.38). 
iconografias sensuais. Corroborando com nosso posicionamento teórico, Edward Conze denuncia a interpretação eurocêntrica sofrida pelo tantra:

Os europeus que escreveram sobre o Tantra muitas vezes tomam partido movidos pela emoção [...] Além disso, o Tantra se presta a provocar-lhes uma indignação moral. Pensam que na história do budismo, uma metafísica abstrata da maior grandeza foi aos poucos dando lugar a uma preocupação com divindades pessoais e com bruxarias, com rituais mágicos sem sentido e toda a espécie de supertições. Uma imoralidade deliberada parece agora substituir a alta austeridade do passado [...] [CONZE, 1973, p. 180)

O eurocentrismo lançou-nos em uma verdadeira nostalgia filosófica, a qual parece ter-se constituído num isolamento, quando não num injusto repúdio aos métodos singulares do tantra e da riquíssima herança espiritual e cultural que o acompanha e naturalmente the pertence. $\bigcirc$ Tantrismo recebeu do ocidente uma injustificável repulsa, fruto da mais inebriante imaturidade intelectual, talvez motivada pela iconoclastia ou pelo despudor de certos ensinamentos, o qual alimentava o olhar suspeito e, por vezes, amedrontado dos teóricos ocidentais, reforçando o exclusivismo cristão. Uma vez mais deparamo-nos com o porquê do característico hermetismo das práticas tântricas. Ao olhar curioso e descuidado, a simbologia e a linguagem alegórica do Tantra podem fomentar conclusões precipitadas e bem longe de suas verdadeiras aspirações.

\section{A transmutação da paixão e o redirecionamento filosófico do Tantra}

As incompreensões sempre fizeram parte da longa trajetória tântrica, contudo acreditamos que a palavra transmutação [entendida como transformação interior) abre novas possibilidades hermenêuticas, as quais poderiam desmistificar muitos maus entendidos doutrinais. David Gordon White (1996), em seu livro The alchemical body, explica que os iniciados tântricos (siddhas budistas e do HațhaYoga) valorizavam em máximo grau a transmutação não apenas dos afetos e emoções, mas também do próprio corpo físico:

Os Siddhas, iogues e alquimistas foram técnicos do concreto: especialistas na transmutação concreta de metais básicos em ouro e na transformação concreta do homem mortal e envelhecido em um super-homem aperfeiçoado e imortal, mestres dos processos naturais [...] do domínio das forças da natureza, incluindo os processos inexoráveis do envelhecimento e da morte [...] (WHITE, 1996, p.7,8, tradução nossa). 
O "homem aperfeiçoado", citado por White, é o adepto tântrico que iniciou uma dura luta contra si mesmo, uma transformação/transmutação de todos os vícios, apegos e desejos egocêntricos. Corroborando com os apontamentos de White, o Lama Anagarika Govinda acredita que a tradição tântrica utilizou a ciência da transmutação não apenas para o avanço espiritual, senão como poderosa ferramenta para adquirir misteriosas faculdades extrassensoriais:

Enquanto os Gregos, e posteriormente os Árabes e alquimistas medievais da Europa (a quem esta ciência foi transmitida pelos Árabes), basearam sua teoria da transmutação dos metais e de outros elementos nesta ideia e tentaram confirmá-la experimentalmente, existia na Índia um grupo de místicos que aplicavam este princípio ao próprio desenvolvimento espiritual e declaravam que aquele que penetrasse na origem e princípio último da unidade no seu próprio interior poderia não somente transformar os elementos do mundo exterior, como também aqueles do seu próprio ser. E alcançando isto, conquistariam este misterioso poder mágico que as escrituras Budistas designaram de siddhi (Pali: iddhi; Tibetano: grub-pa), um poder que é igualmente efetivo no mundo espiritual e no material. Nestas bases, se diz que certos iogues adiantados testavam seus logramentos, exercitando seus poderes de transmutação sobre elementos materiais (GOVINDA, 1995, p. 56-57).

Seja como for, ao longo de toda a jornada espiritual, o praticante tântrico deve estar consciente e pré-disposto a realizar uma transformação interior - superar vícios, maus costumes, defeitos, manias etc - - . método tântrico nos coloca frente a frente com nossos piores inimigos psicológicos, a fim de extrairmos a sabedoria que ali existe de forma latente. Acreditamos que o método transmutatório é um dos pontos altos da análise filosófica aplicada ao tantrismo; perceber uma mudança real no comportamento humano a partir de práticas espirituais é um fenômeno relevante para um observador científico, pois, in loco, é possível experimentar o quanto a mente e, por consequência, a personalidade são passíveis de mudanças significativas, indicando, assim, a eficácia da religião no seu propósito de ajudar a humanidade. Kalu Rinpoche (1999) admite que a transformação das emoções conflituosas em claridade e estabilidade mental está na raiz doutrinal do budismo vajrayāna. Ao reconhecer a impermanência de todos os fenômenos subjetivos, tratando-os com indiferença, surge no praticante um novo estado de claridade-vacuidade, repleto de sabedoria e passividade - este é o sinal inequívoco de que o processo de transmutação interior se iniciou -. 
Tsong-Khapa ${ }^{12}$, em seu comentário a Guhyasamāja Tantra ${ }^{3}$, ensina-nos que, antes de alcançarmos a beatitude mística, necessitamos conhecer e experimentar nossos apegos a fim de transmutá-los em sabedoria espiritual. "A paixão nos leva ao inferno, mas o experiente na arte do caminho, pelo poder da sabedoria, a transforma em liberação e beatitude" (KHAPA, 2010, localização 9467, tradução nossa) ${ }^{14}$.

"A paixão nos leva ao inferno!". Com esta afirmação de Tsong-Khapa, faremos uma breve e interessante digressão cultural em nossos estudos. Na mitologia grega, vemos todo o esplendor semiótico da clássica descida ao Hades. Célebres personagens - Hércules, Ulisses, Orfeu - desceram às gélidas profundezas subterrâneas, para "retornarem" purificados pela "sabedoria infernal".

O cão do Hades representa o terror da morte; simboliza os próprios infernos e o inferno interior de cada um. É de se observar que Hércules o levou de vencida, usando tão-somente a força de seus braços e que Orfeu, "por uma ação espiritual", com os sons irresistíveis de sua lira mágica o adormeceu por instantes [...] $\bigcirc$ monstruoso guardião do Hades só pode ser dominado sobre a terra, quer dizer, por uma violenta mudança de nível e pelas forças pessoais de natureza espiritual (BRANDÃO, 2004, p. 243).

O décimo primeiro trabalho de $\operatorname{Hércules}^{15}$, por exemplo, simboliza a katàßaívw (catábases), isto é, a "descida" ou "ir para baixo". Conforme Junito Brandão (2004), este termo grego representa o supremo rito iniciático, é a "descida" alegórica ao interior da própria psiquê, condição sine qua non para a transformação espiritual. Essa descida iniciática está estreitamente relacionada com as Escolas de Mistérios da Grécia Antiga, destacando-se, sobretudo, os ritos de Elêusis e os

12 Tsong-Khapa é, sem dúvida, a principal influência teórica deste artigo. Nascido no Tibete, viveu durante o século XIV, fundador da Escola Gelug, foi decisivo para o desenvolvimento do tantrismo medieval, bem como para a expansão monástica do budismo Tibetano, escreveu importantes tratados, destacando-se, sobretudo, um dos mais generosos comentários à Guhyasamāja Tantra: Brillant IIlumination of the Lamp of the Five Stages.

${ }^{13}$ Uma das mais antigas e principais obras tântricas do budismo, de acordo com Victor M. Fic [2003) aproximadamente no ano 300 d. C., a Guhyasamāja Tantra, recebeu seu formato final após uma longa trajetória e já havia iniciado sua disseminação dentre as Escolas budistas, ainda que de forma propedêutica e hermética. Francesca Fremantle (1983), contudo, adverte que a data precisa da composição desta obra ainda é um problema insolúvel. Segundo a autora, alguns especialistas sugerem o terceiro século da era cristã como data provável da formatação final da obra, como é o caso de Bhattacharyya. Winternitz, ao contrário, acredita que sua composição aconteceu entre os séculos VIII e X d. C. A Escola japonesa contemporânea, por sua vez, coloca-o no século VIII d. C. Por fim, Alex Wyma, indica o século $\mathrm{V}$ como a data mais provável de sua composição. Para maiores esclarecimentos Cf. FREMANTLE, 1983, p. 14.

${ }^{14}$ A obra Brillant Illumination of the Lamp of the Five Stages, escrita por Tsong-Khapa, será citada de forma diferente das demais literaturas, porque foi consultada por meio do leitor digital Kindle, o qual não utiliza a referência numérica à qual estamos habituados (no leitor Kindle não aparece a página, mas a localização, esta não segue uma ordem crescente). Portanto, a citação terá o ano da obra seguida de sua "localização", conforme o leitor digital mencionado.

${ }^{15} \mathrm{O}$ décimo primeiro trabalho de Hércules é representado na mitologia grega pela busca do cão Cérbero. 
mistérios órficos. "A viagem subterrânea, durante a qual os encontros com os monstros míticos configuram as provações de um processo iniciático, era, na realidade, um reconhecimento de si mesmo, uma rejeição dos resíduos psíquicos inibidores [...]" (BENOIST apud BRANDÃO, 2004, p. 114).

A toda "descida" expiatória sucede uma exaltada "subida", uma "ascenção" vertical em direção à pureza elementar, ao domínio interior das forças sutis; a essa "subida" iniciática os gregos chamaram Aváßaoıs (anábasis). $\bigcirc$ mito de Hércules expressa fidedignamente a mística "descida" dos heróis, com todos os seus perigos, e a sua "subida" triunfal, que pode ser simbolizada por todo indivíduo que busca uma transformação místico-espiritual. $\bigcirc$ herói mitológico grego configura-se como o arquétipo do "homem purificado", aquele que triunfou sobre suas próprias provas iniciáticas, recebendo a meritória coroa da virtude. Joseph Campbell resume a aventura do herói no seguinte diagrama:

[...] Além do limiar, então, o herói inicia uma jornada por um mundo de forças desconhecidas e, não obstante, estranhamente intimas, algumas das quais o ameaçam fortemente (provas), ao passo que outras lhe oferecem uma ajuda mágica (auxiliares). Quando chega ao nadir da jornada mitológica, o herói passa pela suprema provação e obtém sua recompensa. Seu triunfo pode ser representado pela união sexual com a deusa-mãe [casamento sagrado), pelo reconhecimento por parte do pai-criador (sintonia com o pai), pela sua própria divinizaçao (apoteose) ou, mais uma vez se as forças se tiverem mantido hostis a ele -, pelo roubo, por parte do herói, da bênção que ele foi buscar (rapto da noiva, roubo do fogo); intrinsecamente, trata-se de uma expansão da consciência e, por conseguinte, do ser (iluminação, transfiguração, libertação). 0 trabalho final é o do retorno. Se as forças abençoaram o herói, ele agora retorna sob sua proteção (emissário); se não for esse o caso, ele empreende uma fuga e é perseguido (fuga de transformação, fuga de obstáculos). No limiar de retorno, as forças transcendentais devem ficar para trás; o herói reemerge do reino do terror (retorno, ressurreição). A bênção que ele traz consigo restaura o mundo (elixir) (CAMPBELL, 1997, p. 137).

Após nossa salutar digressão, voltemos ao oriente. Analisando o mito do herói grego a partir da perspectiva tântrica, percebemos contrastes inevitáveis. Os mestres do tantra parecem compreender bem a simbólica passagem pelos infernos interiores, que todo iniciado deve passar, antes de alcançar a beatitude mística. Seu método poderia ser traduzido do seguinte modo: "experimente as paixões, entre nas camadas mais recônditas da própria subjetividade, encontre seus piores 'inimigos'desejos e apegos - torne-se uma testemunha deles, não os reprima, compreenda-os intimamente, perceba a vacuidade dos mesmos e retorne purificado, transformado pela mesma energia que outrora lhe havia condenado." $O$ antes demoníaco desejo 
converte-se, por meio de um acurado treinamento tântrico, em suprema liberação, como nos ensina Tsong-Khapa:

Para aqueles que ainda possuem uma compreensão de discípulo, as energias do vício servem como condicionamento do próprio vício, uma vez que eles não entendem a realidade dos vícios. Se eles conhecessem a realidade, essas energias transformar-se-iam na causa da iluminação (KHAPA, 2010, localização 9392, tradução nossa).

Vale ressaltar que nem todos os praticantes estariam preparados para utilizar o vício como objeto de liberação. No exemplo acima, o texto faz menção à compreensão de discípulo, em uma clara alusão às limitações do mesmo, isto é, cada estudante da arte tântrica possuiria um determinado nível iniciático, o qual lhe facultaria um específico método de desenvolvimento, sempre adequado ao grau de instrução que possui. Alexandra David-Néel, em seu livro Iniciações Tibetanas, esclarece:

O que é julgado necessário é uma espécie de transmutação da substância de que é feito o discípulo. As forças nele existentes não devem ser destruídas, mas metodicamente dirigidas para os canais convenientes. $O$ principiante nadjorpa deve aprender a regular e combinar as tendências antagônicas que descobre em si mesmo, para obter os resultados desejados. Essa "combinação" de forças contrárias, o adepto inteligente dessas teorias pratica-a, mesmo deixando-se levar por suas paixões, seja com uma finalidade experimental, ou simplesmente porque proporciona a si mesmo um prazer de ordem inferior: vingança, luxúria ou outro qualquer. A finalidade desejada, neste último caso, é evitar, em parte ou totalmente, os resultados espirituais nefastos destas ações (NÉEL, [s. d] p. 146, 147).

Ao experimentar as paixões, o discípulo pode analisar com maior clareza e exatidão a sua verdadeira natureza. Sentindo em sua própria mente as oscilações dos vícios, pode o praticante tântrico aperfeiçoar sua compreensão sobre o mesmo, extraindo informações relevantes de sua própria experiência, tais como: Em que momento o vício se manifesta? Quando é mais forte? Quanto tempo persiste seus efeitos? De fato, com tenacidade e prática constante o praticante tântrico percebe que o desejo tem um pico de ebulição, é um desafio momentâneo, jamais permanente, absolutamente temporário, passado o momento crítico o desejo perde força e o simulacro do apego é descoberto pela consciência. Com tais evidências empíricas, o método tântrico é capaz de fornecer respostas satisfatórias referentes à superação dos desejos e prazeres, pois, in loco, presenciou suas manifestações - sem reprimi-las - por meio de uma mente treinada, vigilante e aberta à compreensão. 
Vejamos uma importante passagem de um dos maiores clássicos da literatura tântrica budista:

Entregando-se à alegria dos desejos prazerosos, por esta prática você logo alcançará a natureza de Buda [...] o sucesso não é obtido através de votos ascéticos e práticas extremadas, mas pode ser atingido brevemente pelo gozo de todos os prazeres. Não implore por comida nem se apegue à mendicância, ao invés, recite o mantra por inteiro e satisfaça todos os desejos (GUHYASAMĀJATANTRA, 1971, p. 46).

Ao contrário da tradição budista theravāda que, muitas vezes, é vítima de uma perigosa repressão das paixões, o praticante do Tantra esforça-se em transformá-las. Busca-se, através de ritos complexos, iniciações místicas, técnicas meditativas que incluem visualizações e mantralizações, o despertar de inúmeras faculdades latentes no ser humano. Trata-se de uma rigorosa disciplina que deve ser mantida diligentemente pelo praticante que aspira algum benefício espiritual; o intelectualismo é substituído por práticas objetivas que visam, sobretudo, à aquisição da insuperável iluminação. Kalu Rinponche, mestre da tradição vajrayāna, ensina um método meditativo simples e objetivo, capaz de neutralizar os efeitos nocivos do desejo. Trata-se da plena consciência dos distintos pensamentos e suas sensações físicas e mentais:

Supondo que um homem veja uma mulher bonita, o desejo faz com que ele experimente logo uma sensação física e mental agradável. Ao mesmo tempo, a cegueira provoca uma vontade de posse, da qual se espera que consolide a experiência de felicidade. No contexto da meditação que visa transformar as emoções, detém-se na sensação de felicidade produzida pelo desejo, sem considerá-la como uma coisa ruim, sem querer rejeitá-la. Fica-se consciente dessa felicidade, lucidamente, e ela é experimentada sem que se deixe levar pela sede que queira possuir o objeto. Assim, a alegria proveniente do desejo não causa nenhum dano (RINPOCHE, 1999, p. 164).

A proposta é transformar/transmutar o homem em um ser mais estético e menos instintivo. Quando o desejo é incapaz de nos arrastar, quando nos contentamos com a simples sensação visual, criamos um terreno fecundo para a tranquilidade interior, para o cultivo de estados superiores, o apego perde consistência e a consciência é redirecionada para o autodomínio. Pouco a pouco, o praticante percebe que na austeridade mental, no domínio do pensamento e das emoções, esconde-se um prazer antes ignorado, porém poderoso. A luxúria transformada em autodomínio confere ao iniciado budista um contentamento insólito, não menos prazeroso, e até mesmo superior ao daquele oriundo dos sentidos externos. 
O tantra ama a completude, a unidade, interessa-se pelo homem integral e não por seus fragmentos, por isso, estimula-o a ser livre, sem dogmas ou excessos de pudor moral. Por que condenar os desejos, as paixões ou os instintos? Elas apontam apenas para a condição humana atual. Ao reprimir os vícios, criamos uma quimera interior, um estranho, um inimigo. A tradição religiosa não admite a totalidade, não sabe viver com ela, a sociedade conformou-se com a periferia, com o fragmento controlado. $\bigcirc$ homem não tem permissão de expressar a sua totalidade, apenas uma pequena parte de nós mesmos é aceita, a parte remanescente é reprimida, é bestial, bárbara, não-civilizada, e o seu infame destino é o exílio. Eis o meio-homem da tradição!

Trata-se de duas naturezas distintas agindo simultaneamente no indivíduo uma "moralizada" (dogmas da tradição) e outra "imoral" (o instinto) -. Percebendo esse dualismo subjetivo, a doutrina tântrica buscou superar tais limitações discriminatórias. Moralidade ou imoralidade devem fundir-se na compreensão sintética dos opostos. Os praticantes do tantra precisam romper com a ilusão da dualidade, retirar do vício todo seu conteúdo negativo; a eterna luta entre bem e mal, virtude e pecado deve ser superada. Essa oposição opressora dos contrários deve ser transmutada pela síntese complementar da realidade, como nos ensina Tsong-Khapa:

Assim como o estrume das cidades enriquece os canaviais, o estrume do vício contido nos bodhisattvas os fortalece em direção à iluminação. E assim como o veneno combinado com o remédio $\mathrm{e}$ o mantra não podem matar, analogamente o vício combinado com a arte e a sabedoria é incapaz de causar qualquer dano (KHAPA, 2010, localização 9403, tradução nossa).

Nada precisa ser negado ou reprimido, o método tântrico é a transformação! Ou seja, aceita e compreende o homem tal qual se apresenta: imperfeito, desejoso, ambicioso, luxurioso. $\bigcirc$ problema não são os vícios em si mesmos, mas exigir do homem algo que ele não possui - a perfeição -. Portanto, o Tantra não reprime as paixões humanas, compreende-as como fenômenos naturais da mente, os quais devem ser utilizados como fio condutor, como primeiro degrau para a beatitude, transformando-os em virtudes seletas da consciência. Ora, transformar vícios em virtudes não seria possível sem o cultivo da sabedoria não-dual, a qual é essencial nesses estudos; transcender o dualismo significa harmonizar-se com a existência.

\section{Vacuidade: a essência da paixão}

Heráclito, o obscuro filósofo de Éfeso, já na Grécia Antiga, demonstrou em seus fragmentos a profundidade da sabedoria dos opostos, do saber "não-dual". Para 
ele, a realidade é um fluxo contínuo, ser e não-ser mesclam-se sinfonicamente na orquestra da vida. $\bigcirc$ movimento é a essência! A matéria encontra identidade no próprio metamorfosear-se, o determinado choca-se com o indeterminado e deles nasce a mais bela harmonia. Depois de Heráclito, o mundo não pode ser mais visto como estável e imóvel, ao contrário, converte-se no devir, num processo, não é mais um destino fixo, senão uma passagem transitória de forças complementares - o visível e invisível, ódio e amor, noite e dia, alto e baixo etc. -

A sabedoria dos opostos de Heráclito nos ensina, por exemplo, que o conhecimento do fenômeno noite não seria possível sem o contato empírico com o fenômeno dia. Analogamente, o homem reconhece-se como gênero masculino, ativo, positivo e viril, porque existe a mulher - passiva, negativa, amável - que é naturalmente do gênero feminino. Sem ela, não haveria distinção, tampouco reconhecimento do próprio homem de sua verdadeira natureza. De igual maneira, o homem gordo julga-se como tal porque os magros assim o permitem. Graças aos opostos, estabelecemos analogias, distinções, compreensões. $\bigcirc$ próprio conceito de bondade não seria possível estabelecê-lo sem que houvesse atos impiedosos no mundo, graças aos ímpios reconhecemo-nos como misericordiosos.

Assim como Heráclito, o budismo mahāyāna, mais especificamente Nāgārjuna e sua Escola Mādhyamikat's, também elaborou um profundo conhecimento acerca da realidade não-dual, por isso, não condena - tampouco exalta - qualquer polaridade. Positivo ou negativo, ambos possuem relevância, condenar o "negativo" é condenar o "positivo", pois um está irremediavelmente atrelado ao outro. São forças complementares, jamais excludentes, estão inexoravelmente unidas. Analisemos abaixo o sutra acintyastava (Elogio ao inconcebível), atribuído a Nāgārjuna, que expressa a unidade existencial:

Unidade e multiplicidade; passado e futuro. Impureza e purificação, verdade e mentira etc.: Como poderiam existir em si mesmo?[...] Por isso você afirmou que assim como o sofrimento surge de um conjunto de obstáculos, como paixão etc. Tanto ele (o sofrimento) como o acúmulo de méritos - a própria libertação - não passa de um sonho. Nascido, não nascido; presente, ausente; livre, aprisionado; quem vê assim vê dualmente: este não conhece a realidade... [...] Assim é o Tathāgata, [assim] é a originação interdependente, assim é a vacuidade, a doutrina verdadeira; é assim

\footnotetext{
${ }^{16}$ Mãdhyamika significa caminho do meio. Considerada por muitos como a mais influente Escola do budismo mahāyāna, Fundada por Nāgārjuna (séc. II d. C.), está baseada principalmente no sutra Prajñapāramitā. Rivaliza em importância filosófica com a Escola Yogacāra, fundada por Asanga. Basicamente, a diferença entre ambas está no fato de que a primeira entende o mundo objetivamente e subjetivamente - como essencialmente vazio, a existência seria um fenômeno produzido e dependente das limitações da própria mente, uma vez superada as limitações, a realidade perde a aparente consistência e alcançamos a visão interior da vacuidade de todos os fenômenos. Ao contrário, a Escola Yogacāra admite que a existência em si mesma está contida na própria mente, ela é o único ser, puro e acabado, todos os fenômenos externos derivam de suas próprias modificações subjetivas. Sobre esse assunto, Cf. RIMPOCHÊ, 2006.
} 
que [a natureza d]as coisas deve ser compreendida. Aquela é a verdadeira natureza da realidade, o sempre assim, a visão crítica, a dimensão mais profunda, a confluência final: quem desperta para aquilo é chamado Desperto (Buddha) (ACINTYASTAVA, 2015, p. $114,115,116,117)$.

A filosofia de Nāgārjuna vai além daquela apresentada por Heráclito, mais do que o reconhecimento teórico da suprema unidade da existência, o mestre budista sustenta a experimentação da vacuidade inerente de todas as coisas e a realidade da originação interdependente $e^{17}$, isto é, os fenômenos duais não possuiriam realidade em si mesmo, são kleśas, ilusões nascidas da própria ignorância, originadas através do contato com o samsara. Eis a grande diferença! A proposta budista, ao contrário da grega, é a experiência, isto é, vivenciar os distintos aspectos da existência através de estados místicos oriundos da própria consciência, e não apenas contentar-se com conhecimentos conceituais. A filosofia de Nāgārjuna busca, sobretudo, uma compreensão ontológica capaz de assegurar uma firme convicção na vacuidade existencial:

Mais do que isso, segundo Nāgārjuna, a originação interdependente, além de um importante fator de relativização ontológica e epistemológica, é a chave para se compreender uma importante condição do real: se todo e qualquer ser é interdependente, vale dizer, se não possui uma natureza autônoma, independente das dos demais seres, ou independentes das condições que o determinam, como se pode falar em um limite ["Koțị") ou de origem (utpanna/utpāda) ou destruição (bhāñga) de qualquer ser? ${ }^{18}$ (ANDRADE, 2012, p. 127).

Khenchen Thrangu Rimpochê, nos comentários ao Dharmadharmatavibhagd', esclarece que todos os fenômenos - subjetivos ou objetivos - são essencialmente vazios (śūnya). Para alcançar a sabedoria Mādhyamikam, deve-se seguir por degraus: no primeiro, compreende-se a realidade dos fenômenos externos como produtos da própria mente; posteriormente, descobre-se que também os fenômenos internos são a mente; por último, alcança-se a visão sinótica de que ambos emergem intrinsecamente de um fio condutor comum: a vacuidade ${ }^{20}$.

${ }^{17}$ Originação interdependente é o fluxo ilusório que mantém os seres enredados na roda do saṃsāra. Em síntese, constitui-se pelos doze elos de conexões causais (ignorância, disposições cármicas, consciência, nome e forma, bases sensoriais, contato, sensação/sentimento, sede/anelo, apego, vir-aser, nascimento, envelhecimento e morte), formando um círculo vicioso e contínuo, o qual impede a liberação espiritual do indivíduo e o faz transmigrar repetidamente por sucessivas vidas.

${ }^{18}$ Desenha-se aqui o grande "nó" etiológico budista, que aponta mais uma vez para a interdependência e a vacuidade de todos os fenômenos: se os seres são, na realidade não nascidos, como segmentar ou identificar com clareza o limite entre causas e efeitos?

${ }^{19}$ Texto mahayanista que trata da distinção entre as aparências fenomênicas e o ser puro.

${ }^{20}$ Cf. RIMPOCHÊ $(2006$, p. 38, 39). 
O erudito mestre Atisha [982-1054 d. C.] ao ser perguntado qual seria o mais elevado de todos os ensinamentos respondeu ao seu discípulo: "O mais elevado dos ensinamentos é a vacuidade que está dotada com a essência da compaixão [...]" (ATISHA, [s.d], p. 3, tradução nossa). De fato, uma vez que o discípulo tenha alcançado uma sólida compreensão acerca da vacuidade, certamente, seu caminho em direção à iluminação espiritual torna-se bem menos tortuoso.

Apresentamos a contribuição de Herbert Guenther e Chögyam Trungpa que exaltam as qualidades não discriminatórias dos textos tântricos, ou seja, por detrás das polaridades existenciais, de forma subjacente, encontra-se a síntese perfeita, a vacuidade, que nada mais é do que o sustentáculo onto-epistemológico da existência:

União não é mais que a experiência rutilante da compreensão, uma suspeita súbita de dois aspectos de toda experiência que se unem repentinamente em uma relação caótica desde o ponto de vista do ambiente experimentado em direção ao ego. $O$ amor e o ódio, por exemplo, se unem. A integridade do ódio, que depende do ambiente do ego, encontra a qualidade egoísta do amor. Subitamente, ódio e amor são uma e mesma coisa, e repentinamente nenhum deles existe [...] No momento da união se produz um choque que não é mais que o descobrimento da verdade (GUENTHER \& TRUNGPA, 2003, p. 25, tradução nossa).

A união entre o amor e o ódio mencionada acima é a percepção de que ambos emergem de um ponto comum: a mente. $\bigcirc$ ódio é a simples ignorância do amor, uma vez que a mente foi totalmente iluminada pela sabedoria búdica, o adepto do tantra percebe a estultícia do ódio, sua insubstancialidade, e, naturalmente, ao invés de sentir emoções negativas, emerge - a partir da compreensão da natureza vazia do próprio ódio - a genuína compaixão, o amor incondicional por todos os seres, resultado da transmutação tântrica interior.

Ao compreender profundamente a unidade primordial, o praticante pode relacionar-se de forma mais lúcida e consciente com os desejos e prazeres, pois compreende que a raiz desses fenômenos, ontologicamente, não difere da própria iluminação, do estado de Buda. Por isso, a abordagem tântrica estimula o praticante a experimentar os prazeres mundanos como método para superá-los. As privações e austeridades possuem seu valor, porém sua eficácia é questionada pelo tantrismo, que se impõe como uma "via alternativa" aos excessos das práticas ascéticas:

O Tantra Guhyasamaja, um dos mais antigos, e também uma das mais sagradas Escrituras do Tantra da Esquerda, parece ensinar exatamente o oposto do que propôs o ascetismo budista. Diz-nos que é certo alcançarmos facilmente o budato se "cultivarmos todos os prazeres sensuais, como desejarmos". Privações e austeridades falham onde a "satisfação dos desejos" consegue êxito. Justamente as ações mais imorais, mais tabus, parecem atrair com maior fascínio 
os seguidores desta doutrina. São incentivados a desafiar as proibições que restringem o alimento permitido aos ascetas. Devese comer carne de elefantes, de cavalos, de cães, e toda a comida e toda a bebida deve ser misturada com imundícies, urina ou carne [...] $\bigcirc$ que se quer aqui é estabelecer um contato proposital entre os sentidos e os objetos que os estimulam, quer por meio de forte atração, quer por repugnância. Por um lado, pode-se chegar à verificação total e à compreensão da futilidade e da relatividade dos prazeres dos sentidos pelo simples fato de experimentá-los (CONZE, 1973, p. 201).

O Budismo Vajrayāna, por exemplo, utiliza-se das mesmas energias destrutivas das paixões para fins altruísticos. Todo o processo filosófico está alicerçado no reconhecimento da natureza impermanente e vazia dos vícios. Por isso, resulta tão importante sentir o gosto das paixões. $\bigcirc$ reconhecimento da vacuidade de todos os fenômenos (negativos ou positivos) garante ao praticante um caminho seguro para consolidar a transmutação dos defeitos em virtudes. A seguir, apresentaremos uma passagem do "Sutra do Caminho da Verdadeira Sabedoria" (texto da linhagem Vajrayana ou tântrico muito importante para a tradição esotérica japonesa da Escola Shingon):

O êxtase supremo da união entre o homem e a mulher é um puro estado de Bodhisattva. A excitação dos sentidos, comparável ao rápido vôo de uma flecha, é um puro estado de Bodhisattva. As carícias trocadas entre homem e mulher são um puro estado de Bodhisattva. Os laços firmes do amplexo amoroso são um puro estado de Bodhisattva. O pleno gozo experimentado pelo homem e pela mulher, que Ihes dá a sensação de serem senhores de tudo, dotados com a liberdade total, é um puro estado de bodhisattva. Contemplar o sexo oposto com olhar de desejo é um puro estado de bodhisattva. A sensação de prazer que o homem e a mulher experimentam quando unidos é um puro estado de Bodhisattva [...] (ADHYARDHASATIKA PRAJANAPARAMITA, 2015, p. 246)

A naturalidade precisa ser reconquistada pelo indivíduo, os olhos da inocência podem ser novamente despertados com técnicas apropriadas de cultivo da estabilidade mental e autodomínio. Se quisermos compreender a essência do tantra, necessitamos abrir o nosso leque hermenêutico e romper com o puritanismo exegético que, por vezes, inconscientemente, habita nossos "melhores" julgamentos. O professor Ricardo Mario Gonçalves faz interessantes observações sobre nossa relação com o prazer bem como com o sutra acima citado:

A leitura deste Sutra há de provocar um choque naqueles leitores para quem a religião é sinônimo de puritanismo e de repressão da dimensão sexual do ser humano. Isso porque o Sutra proclama a pureza de todas as coisas, quando contempladas em sua vacuidade, sem apego, inclusive do ato sexual cujas etapas são descritas numa 
linguagem bem realista. Não se trata, evidentemente, de entronizar o sexo no centro de nossas vidas como faz certa sexolatria muito em voga no mundo ocidental nos dias de hoje, mas simplesmente de constatar que o sexo, quando praticado espontaneamente e naturalmente, sem maiores apegos, é tão puro quanto outros aspectos da existência humana (GONÇALVES, 2015, p. 257).

A sexualidade ${ }^{21}$ é uma dimensão importante e não rejeitada pelo tantra, como podemos observar na citação acima. Sobre este ponto, Victor M. Fic admite que “Em algumas Escolas do budismo tântrico a união com Sakti, embora contendo objetivos ritualísticos, é real no sentido físico, envolvendo união sexual sem erotismo [...]" (FIC, 2003, localização 776, tradução nossa). A expressão "sem erotismo" deve ser bem compreendida, pois, na perspectiva tântrica, a sexualidade transforma-se na expressão física do genuíno afeto, como bem assinalou o professor Gonçalves em sua citação. Trata-se da superação absoluta da concupiscência e do erotismo luxurioso. Mais do que um simples fenômeno social, o sexo converte-se em objeto de culto, precioso suporte soteriológico capaz de transmutar a química corporal em mente pacificada. Sobre esse tópico, Mircea Eliade enfatiza a importância da prática sexual no desenvolvimento do budismo tântrico e sua função salvacionista: "O maithuna é conhecido desde os tempos védicos, mas caberá ao tantrismo transformá-lo em instrumento de salvação" (ELIADE, 2012, p. 213).

O sexo-yoga ou maithuna (palavra sânscrita que usualmente é interpretada como união sexual) lança os corpos dos amantes na terrível arena do desejo: neste duro combate, a vitória é consolidada quando se transcende a lascívia, permitindo que a mente repouse sobre sua própria essência luminosa, sem interferência do ego. Com semelhante disciplina, a mulher converte-se no centro das operações alquímicas, um ser divino, capaz de conferir sublimes estados de consciência ao seu parceiro conjugal. Utilizando as técnicas apropriadas, o iniciado tântrico transcende as paixões corporais, sua consciência percebe a vacuidade e impermanência de todas as paixões luxuriosas, sente-se superior a elas e absolutamente livre de suas influências, situando-se, assim, em perfeito equilíbrio interior, abrindo possibilidades reais para a obtenção da insuperável iluminação.

Como já mencionamos anteriormente, existe uma proposta salvacionista muito clara no método tântrico e a sexualidade foi naturalmente incluída nesse projeto soteriológico. A polêmica introdução do maithuna deixa claro a audácia e o destemor do iniciado tântrico em enfrentar todos os riscos e perigos das paixões sensuais. Roque Severino também acredita na inclusão da sexualidade tântrica no contexto budista, porém adverte que esta é uma técnica seleta que deve ser entregue ao discípulo com muita responsabilidade:

\footnotetext{
${ }^{21}$ Muitos autores divergem sobre os detalhes da relação entre sexualidade e religião no tantrismo. 0 assunto é exaustivo e necessitaríamos de um maior número de laudas para exauri-lo de forma satisfatória, razão pela qual preferimos fazer apenas algumas considerações propedêuticas, deixando para um trabalho posterior o aprofundamento sistemático da questão.
} 
Já que o budismo tântrico usa o método da transformação em vez da supressão ou extirpação, os "apetites" como o desejo sexual não estão fora dos limites para praticantes avançados. De fato, os mais altos tantras trabalham com as energias do corpo para avançar o progresso de uma pessoa rumo à iluminação. Nem todos nesse caminho têm um parceiro, mas para alguns é uma vantagem (SEVERINO, 2010, p.127).

O objetivo último do sexo-yoga é alcançar a total extirpação do ego. Trata-se da perfeita harmonia entre mente e corpo, os quais devem estar em equilíbrio, para se tornarem dóceis instrumentos no duro caminho rumo à transcendência do ego. Além da transmutação dos desejos e paixões, Severino aponta a necessidade do guru. $\mathrm{Na}$ verdade, somente o mestre espiritual estaria em condições de determinar o momento exato em que o discípulo estaria em condições ou não de receber determinados ensinamentos relativos à sexualidade, como adverte Edward Conze:

O Buda declarou com satisfação "nada ter escondido dentro de sua mão fechada" no que se relaciona ao conhecimento conducente à salvação. O Tantra, ao contrário, supõe que os métodos realmente eficazes para a salvação e o seu emprego adequado não se aprendem nos livros, mas só podem ser ensinados pelo contato direto com um instrutor espiritual, chamado guru [CONZE, 1973, p.185].

Evidentemente, não estamos defendendo aqui qualquer tipo de hedonismo, senão uma visão tântrica acerca da vida. De fato, qualquer ação humana pode converter-se em prisão psicológica, o problema não está no fenômeno externo, mas na disposição da mente para desfrutar das ações sem se apegar a elas. Por isso, a proposta do tantra é converter o peso da culpa em mente desperta. $\bigcirc$ "pecado" da ação está rigorosamente dentro do próprio homem, com mente lúcida, atenta e vigilante, o indivíduo pode agir sem se apegar aos frutos da ação, isto é, pode comer sem o peso da gula, relacionar-se com o sexo oposto sem o fardo da luxúria, apresentar aos amigos alguma conquista material isento de qualquer orgulho etc. Em suma, a proposta tântrica é abrir horizontes! É mostrar ao homem que, com mente estável e vigilante, o prazer e o desejo deixam de ser entraves à iluminação e transformam-se em seus maiores aliados.

\section{Considerações finais}

Despertar do sono onírico e evidenciar a ilusão na qual estamos inseridos, perceber que, na realidade mais profunda de nós mesmos, jamais fomos afetados por coisa alguma, que todo sofrimento é transitório e irreal - tais considerações só são 
possíveis ao homem iluminado -. Por isso, o mistério central está ancorado na sua figura. A rigor, nenhum outro indivíduo teria condições de conceituar sobre a realidade metafísica, suas limitadas possibilidades o traem, lançando-o no terrível labirinto das teorias; somente um indivíduo desperto poderia falar daquilo que experimentou. Só ele teria condições de perceber empiricamente a verdade búdica e sentir a profunda vacuidade de si mesmo, não diferenciado de qualquer outro fenômeno. Seguramente, o intelecto não poderia nos fornecer tal evidência, poderia conceituar sobre o assunto, mas sem tirar qualquer proveito real de suas conjecturas. Não obstante, o enfoque principal do budismo é a transformação do próprio homem, conscientizando-o de sua realeza oculta, advertindo-o sobre o estado de ignorância no qual se encontra. $\bigcirc$ tantrismo anela pela liberação psicológica e espiritual do ser humano, ou seja, que cada indivíduo torne-se um Buda, um ser desperto; nenhuma força adventícia pode fazer isso, a menos que se empenhe duramente no exercício das práticas budistas, dificilmente o homem terá êxito e suas conclusões acerca da realidade serão sempre pouco elucidativas e inclinadas a um perigoso subjetivismo, que poderia mais afastá-lo do que aproximá-lo da experiência mística do vazio iluminador.

Concluímos nosso artigo enfatizando o caráter humanístico do tantrismo. Como vimos desde as primeiras páginas, o foco das discussões tântricas gravitou sempre ao redor das questões humanas, fenômenos subjetivos que podem causar grande sofrimento se não forem devidamente compreendidos. Pode-se dizer que a meta última de todas as práticas e ensinamentos tântricos, cada qual ao seu modo, é o despertar da iluminação espiritual e a aniquilação definitiva do sofrimento.

\section{Referências bibliográficas}

ACINTYASTAVA. Tradução e comentários Clodemir Andrade In: GONÇALVES, Ricardo Mario; MONTEIRO, Joaquim; REDYSON, Deyve (Org.). Antologia Budista. São Paulo: Fonte Editorial, 2015.

ADHYARDHASATIKA PRAJANAPARAMITA. Tradução e comentários Gonçalves Ricardo Mario In: GONÇALVES, Ricardo Mario; MONTEIRO, Joaquim; REDYSON, Deyve (Org.]. Antologia Budista. São Paulo: Fonte Editorial, 2015.

ANDRADE, Clodomir. Veredas ao inconcebível. In: GONÇALVES, Ricardo Mario; MONTEIRO, Joaquim; REDYSON, Deyve (Org.). Antologia Budista. São Paulo: Fonte Editorial, 2015.

ATISHA. Atisha: sus Enseñanzas. Trad. Upasaka Losang Gyatso. Compiladas por Chegom Sherab Dorje. Clássicos da índia, [s.d].

BOISSELIER, Jean. A Sabedoria do Buda. Rio de Janeiro: Objetiva, 2002. 
BRANDÃO, Junito. Mitologia Grega. V. I. Petrópolis: Vozes, 2004.

BUGAULT, Guy; KAPANI, Lakhsmi. O Buda e o aprofundamento da vida moral no budismo. In: CANTO-SPERBER, Monique (org). Dicionário de Ética e Filosofia Moral. São Leopoldo: Editora Unisinos, 2007.

CAMPBELL, Joseph. O heroi de mil faces. Trad. Adail Ubirajara Sobral. São Paulo: Cultrix/ Pensamento, 1997.

CONZE, Edward. Budismo: sua essência e desenvolvimento. Rio de Janeiro: Civilização Brasileira, 1973.

DALAI LAMA XIII. A Brief Guide to the Buddhist Tantras. In: MULLIN, Glenn H. The Dalai Lamas on tantra, translated, edited, and introduced by Glenn H. Mullin. Ithaca: Snow Lion, 2006.

DALAI LAMA XIV. A Survey of the Paths of Tibetan Buddhism. London: 1988. Disponível em: <http:// www.geocities.com/ Athens/lthaca/4886/ dalai2.htm>. Acesso em: 20 fev. 2016.

DAVID-NÉEL, Alexandra. Iniciações Tibetanas. São Paulo: Pensamento, [s. d.].

DUROZOI, Gérard e ROUSSEL, André. Dicionário de Filosofia. Campinas/SP: Papiros, 1993.

ERNEST, Yassine Bendriss. Breve Historia del Budismo. Madrid: Ediciones Nowtilus, 2014.

FEUERSTEIN, Georg. Tantra: The path of ecstasy. Boston \& London: Shambhala Publications, 1998.

FIC, Victor M. The Tantra. New Dheli: Abhinav Publications, 2003.

FLOOD, Gavin. The Tantric body: The Secret Tradition of Hindu Religion. London: I.B. Tauris, 2006.

FREMANTLE, Francesca. Guhyasamāja tantra: A critical study of the guhyasamāja tantra. Tese (doutorado em Estudos Orientais e Africanos) University of London, London, 1971.

GNERRE, Maria Lucia Abaurre. Religiões Orientais: Uma introdução. Volume 1: Tradições da Índia - Do Veda ao Yoga. João Pessoa. Ed. Universitária UFPB, 2010.

GONÇALVES, Ricardo Mario. Adhyardhasatika Prajanaparamita. In: GONÇALVES, Ricardo Mario; MONTEIRO, Joaquim; REDYSON, Deyve (Org.). Antologia Budista. São Paulo: Fonte Editorial, 2015. 
GUHYASAMĀJA TANTRA. A critical study of the guhyasamāja tantra. Trad. Francesca Fremantle. Tese (doutorado em Estudos Orientais e Africanos) University of London, London, 1971.

GUHATTHAKASUTTAM. Tradução e comentários Ricardo Sasaki In: GONÇALVES, Ricardo Mario; MONTEIRO, Joaquim; REDYSON, Deyve (Org.]. Antologia Budista. São Paulo: Fonte Editorial, 2015.

GUENTHER V. Herbert \& TRUNGPA, Chögyam. El amanecer Del Tantra. Trad. Horácio Gonzáles Trejo. Barcelona: Editorial Kairós, 2003.

GYATSO, Geshe Kelsang. Budismo Moderno: $\bigcirc$ caminho de compaixão e sabedoria. São Paulo: Tharpa Brasil, 2016.

KHAPA, Tsong. Brillant IIlumination of the Lamp of the Five Stages. Trad. Robert A. F. Thurman. New York: Columbia University, 2010.

NINA, Ana Cristina Lopez. Ventos da Impermanência. um estudo sobre a ressignificação do Budismo Tibetano no contexto da diáspora. São Paulo: Edusp, 2006.

RINPOCHE, Kalu. Ensinamentos Fundamentais do Budismo Tibetano (Budismo Vivo, Budismo Profundo, Budismo Esotérico). Brasília: Shisil, 1999.

RIMPOCHÊ, Khechen Thrangu. Distinguindo Darma e Darmata $(O$

Dharmadharmatavibhaga de Buda Maitréya). Porto Alegre: Bodigaya, 2006.

SAID, Edward. Orientalismo: o Oriente como invenção do Ocidente. São Paulo: Companhia das Letras, 1990.

SEVERINO, Roque Enrique. Manual de Budismo. São Paulo: Edição do autor, 2010.

SNELLGROVE, D.L. Buddhist Himalaya. London: Bruno Cassier, 1957.

WHITE, David Gordon. The alchemical body. Siddha traditions in medieval India. Chicago/London: The University of Chicago Press, 1996.

ZIMMER, Heinrich. Filosofias da Índia. São Paulo: Palas Athena, 2015. 